\title{
Complete laparoscopic total mesorectal excision with an intersphincteric resection and coloplasty pouch anal anastomosis for lower rectal cancer
}

\author{
Yuji Toiyama, Junichiro Hiro, Hiroki Imaoka, Hiroyuki Fujikawa, Hiromi Yasuda, Minako Kobayashi, Toshimitsu Araki, \\ Shigeyuki Yoshiyama, Masaki Ohi, Yasuhiro Inoue, Yasuhiko Mohri and Masato Kusunoki \\ Department of Gastrointestinal and Pediatric Surgery, Division of Reparative Medicine, Institute of Life Sciences, \\ Graduate School of Medicine, Mie University, Mie, Japan
}

\begin{abstract}
:
This pilot study aimed to develop a new technique, complete laparoscopic total mesorectal excision (TME) with an intersphincteric resection (ISR) and coloplasty pouch anal anastomosis to avoid any further abdominal incision other than laparoscopic port sites, and to assess the impact on short-quality of life and oncological outcomes of this technique. After laparoscopic TME, large bowel was dissected at the level of the promontory. Then, laparoscopic construction of the coloplasty pouch was performed. Simultaneously, a rectal specimen with ISR was excised using the transanal approach. Coloplasty pouch was gently pulled from pelvic thorough anal and a hand-sewn coloplasty pouch anal anastomosis was created. We had performed 8 surgeries using the new technique. Though one patient developed pelvic infections, but intestinal continuity could be maintained and no local and distant recurrence was recognized in other patients. We foresee this novel approach to have significant clinical potential for lower rectal cancer patients with ISR.
\end{abstract}

Keywords:

laparoscopy, intersphincteric resection, coloplasty

J Anus Rectum Colon 2017; 1(1): 35-38

\section{Introduction}

Total mesorectal excision (TME) with coloanal anastomosis (CAA) is a well-established surgical technique for low rectal cancer ${ }^{1,2)}$. However, poor bowel function may be expected with straight CAA because the reservoir function of the excised rectum is lost and some damage to the anal sphincters are induced when preoperative chemoradiotherapy (CRT) and/or intersphincteric resection (ISR) was performed $^{3}$. In such circumstances, restoration of the rectal reservoir by creation of a colonic J-pouch or performance of coloplasty pouch improved early bowel function ${ }^{3}$. Laparoscopic surgery is now widely used for the treatment of low rectal cancer ${ }^{4}$. In cases of laparoscopic ISR (Lap-ISR), a rectal specimen is excised using the transanal approach, which does not require laparotomy. In some cases (e.g., patients with obesity, bulky sphincters, or a short descending colon), a colonic J-pouch is not created after Lap-ISR without laparotomy. We herein describe a technique involving complete laparoscopic TME with ISR and coloplasty pouch anal anastomosis to avoid any further abdominal incisions other than those at the laparoscopic port sites.

\section{Methods}

\section{Patients}

From April 2014 to October 2015, eight patients with low rectal adenocarcinoma (lower edge $<4 \mathrm{~cm}$ from anal verge) were evaluated to determine the feasibility of this novel operation method. Details of patients are given in Table 1. Preoperative evaluation included physical examination, colonoscopy with biopsy, endorectal ultrasonography, computed tomography from chest to pelvis, and pelvic magnetic resonance imaging. Digital examination was performed by the surgeon to evaluate the fixation and location of the tumor from the anal verge. Patients were staged using the tumor, node, metastasis (TNM) classification. Neoadjuvant CRT 
Table 1. Patients Characteristics.

\begin{tabular}{|c|c|c|c|c|c|c|c|c|c|c|c|c|}
\hline Sex & Age & Location & nCRT & $\begin{array}{l}\text { Pathological } \\
\text { Stage }\end{array}$ & $\begin{array}{l}\text { Operation } \\
\text { Method }\end{array}$ & Time & $\begin{array}{l}\text { Blood } \\
\text { Loss }\end{array}$ & SSI & Leakage & EPSBO & WIS & $\begin{array}{l}\text { Follow } \\
\text { up }\end{array}$ \\
\hline Male & 76 & AV 2.0 & yes & $\begin{array}{c}\text { Stage 0 } \\
\text { (T0, n0, M0, } \\
\text { ly0, v0) }\end{array}$ & $\begin{array}{l}\text { LAP TME with } \\
\text { subtotal ISR }\end{array}$ & 309 & 40 & No & negative & negative & 18 & 12 \\
\hline Female & 48 & AV 3.0 & yes & $\begin{array}{c}\text { Stage I } \\
\text { (T2, n0, M0, } \\
\text { ly0, v0) }\end{array}$ & $\begin{array}{l}\text { LAP TME with } \\
\text { partial ISR }\end{array}$ & 310 & 93 & $\begin{array}{c}\text { Yes } \\
\text { (organ) }\end{array}$ & negative & negative & 7 & 13 \\
\hline Male & 44 & AV 2.0 & none & $\begin{array}{c}\text { Stage I } \\
\text { (T1b, n0, M0, } \\
\text { ly0, v0) }\end{array}$ & $\begin{array}{l}\text { LAP TME with } \\
\text { partial ISR }\end{array}$ & 381 & 183 & No & negative & negative & 10 & 19 \\
\hline Female & 72 & AV 3.5 & none & $\begin{array}{c}\text { Stage II } \\
\text { (T3, n0, M0, } \\
\text { ly0, v0) }\end{array}$ & $\begin{array}{l}\text { LAP TME with } \\
\text { partial ISR }\end{array}$ & 304 & 33 & No & negative & negative & 6 & 16 \\
\hline Female & 48 & AV 4.0 & none & $\begin{array}{c}\text { Stage I } \\
\text { (T1b, n0, M0, } \\
\text { ly1, v0) }\end{array}$ & $\begin{array}{l}\text { LAP TME with } \\
\text { partial ISR }\end{array}$ & 219 & 50 & No & negative & negative & 2 & 15 \\
\hline Female & 72 & AV 2.0 & none & $\begin{array}{c}\text { Stage I } \\
\text { (T1b, n0, M0, } \\
\text { ly1, v0) }\end{array}$ & $\begin{array}{l}\text { LAP TME with } \\
\text { partial ISR }\end{array}$ & 300 & 18 & No & negative & negative & 12 & 30 \\
\hline Female & 77 & AV 3.0 & none & $\begin{array}{c}\text { Stage I } \\
\text { (T1b, n0, M0, } \\
\text { ly } 1, \mathrm{v} 0)\end{array}$ & $\begin{array}{l}\text { LAP TME with } \\
\text { partial ISR }\end{array}$ & 300 & 46 & No & negative & negative & 7 & 19 \\
\hline Female & 34 & AV 2.0 & none & $\begin{array}{c}\text { Stage I } \\
\text { (T1b, n0, M0, } \\
\text { ly1, v0) }\end{array}$ & $\begin{array}{l}\text { LAP TME with } \\
\text { partial ISR }\end{array}$ & 268 & 1 & No & negative & negative & 9 & 22 \\
\hline
\end{tabular}

nCRT: neoadjuvant chemoradiotherapy; SSI: Surgical Site Infection; EPSBO; Early Postoperative Small Bowel Obstruction; AV: Anal Verge; LAP: laparoscopic; TME: Total Mesorectal Excision; ISR; Intersphincteric Resection; WIS: Wexner incontinence scale

(conventional external radiation therapy [45 Gy in 25 fractions] and concurrent chemotherapy with irinotecan and S1) was administered to patients with tumors staged as T3, T4, or N1 before the operation. The time interval between preoperative CRT and surgery was 6 to 8 weeks in patients with neoadjuvant CRT.

\section{Surgical technique}

\section{Laparoscopic phase}

We herein describe our surgical technique in the laparoscopic phase. We prefer to perform lymph node dissection around the inferior mesenteric artery and preserve the left colic artery. When an insufficient length of a reconstructed intestine was available, the splenic flexure was lowered to maintain the length. After TME was performed with preservation of the hypogastric nerves and pelvic plexuses, the large bowel was dissected at the level of the promontory. Later laparoscopic construction of the coloplasty pouch was performed (Supplementary Figure 1). A 6-cm longitudinal incision was made between the tenia along the antimesenteric side of the descending colon, starting $6 \mathrm{~cm}$ above the distal cut end (Figure 1A). Lateral traction by stay sutures showed how the transverse coloplasty pouch was formed, and the colostomy was closed transversely by placement of three stay sutures (4-0 PDS) at regular intervals (Figure 1B). Two surgical staples were placed to close the incision transversely and reinforce the suture (4-0 PDS) at the crossing point of the staples (Figure 1C).

Perianal phase
Perianal rectal dissection began simultaneously with the start of the laparoscopic coloplasty pouch construction. The mucosa was usually cut circumferentially at the dentate line. A 5-mm mucosectomy is performed, and the mucosal stump was closed with sutures. The internal sphincteric muscle was partially (Figure 2A) or subtotally resected (Figure 2B, C), depending on the distance from the dentate line to the distal tumor edge. On the other hand, a circular incision was created in the anoderm if the tumor was located at the anal canal, facilitating total ISR (Figure 2D). After closure of the rectal stump, perianal dissection was performed along the medial plane of the external sphincteric muscles and the levator ani muscle until the level of laparoscopic pelvic dissection was reached. The specimen was then delivered anally.

The coloplasty pouch was gently pulled in the pelvic-toanal direction, and a hand-sewn coloplasty pouch anal anastomosis was created. The position of the coloplasty pouch was checked by re-laparoscopy to avoid any inadvertent mesenteric twisting. A closed suction drain was placed deep into the presacral space for pelvic drainage, and a decompressive catheter was inserted perianally. A diverting ileostomy was created, and the abdominal incisions for the port sites were closed using absorbable sutures.

\section{Results}

Table 1 shows patients characteristics including clinicopathological findings, postoperative complication and func- 


\section{(A)}

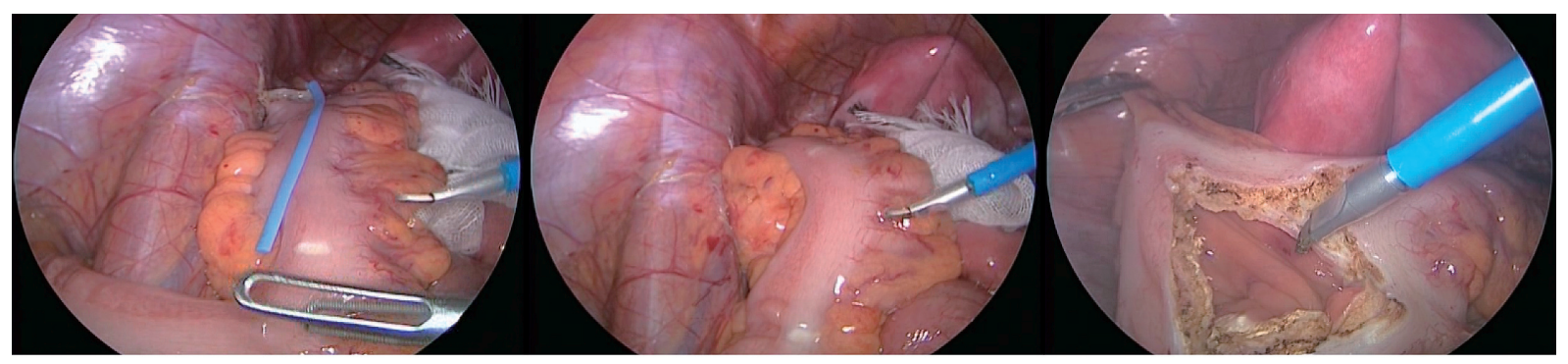

(B)

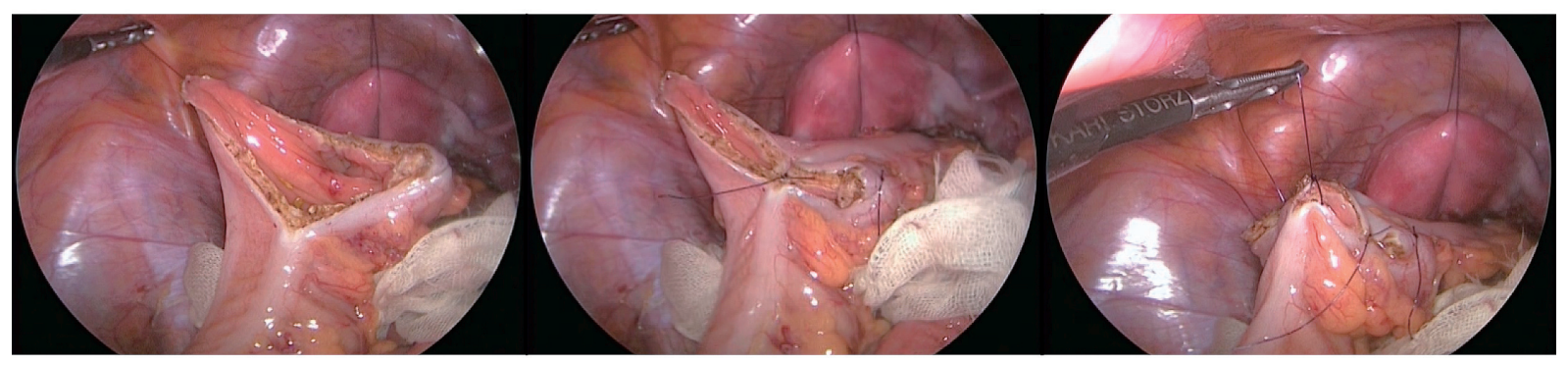

(C)

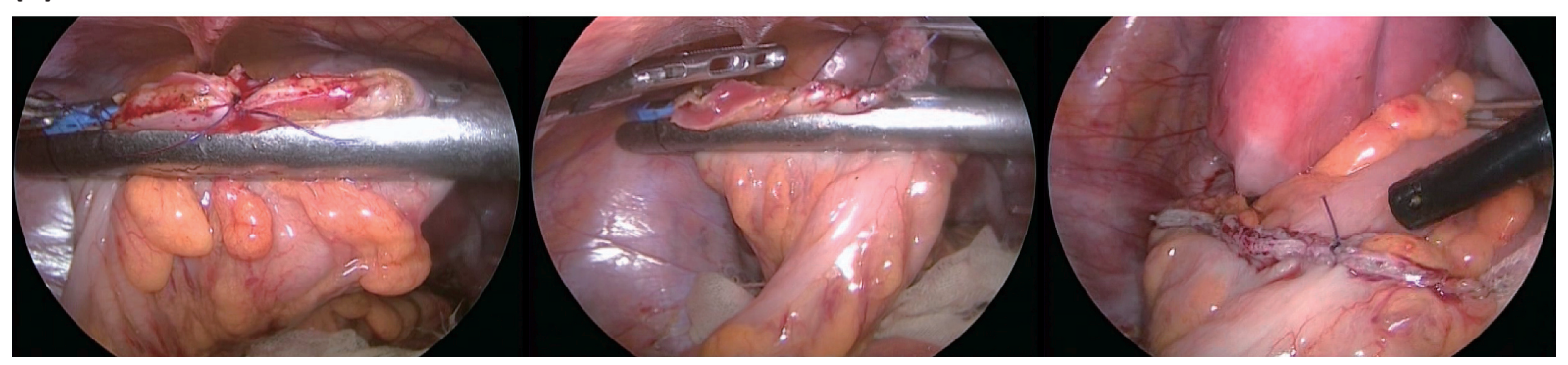

Figure 1. Surgical steps of laparoscopic construction of coloplasty pouch. (A) Opening the colonic lumen longitudinally. (B) Lateral traction by stay sutures. (C) Closing the colonic lumen transversely.

(A)

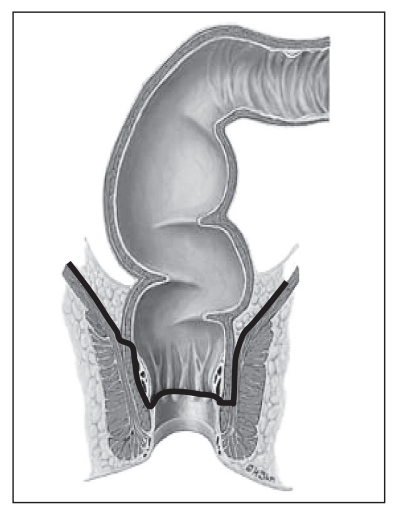

(B)

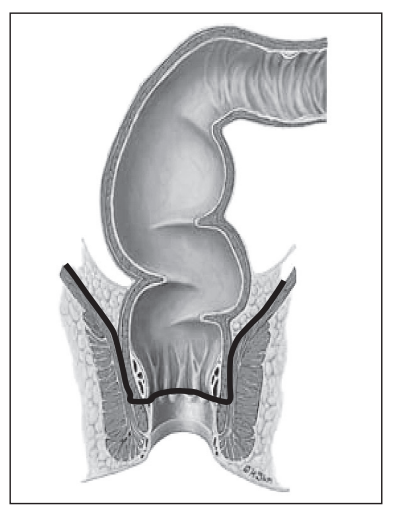

(C)

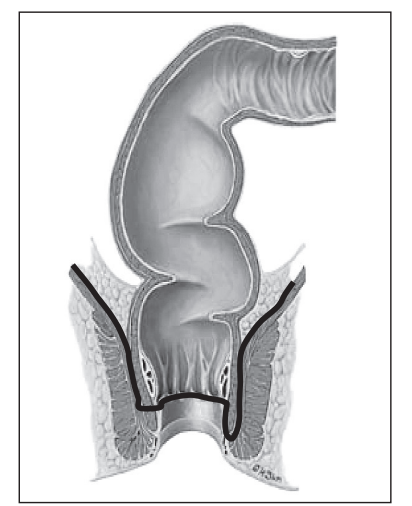

(D)

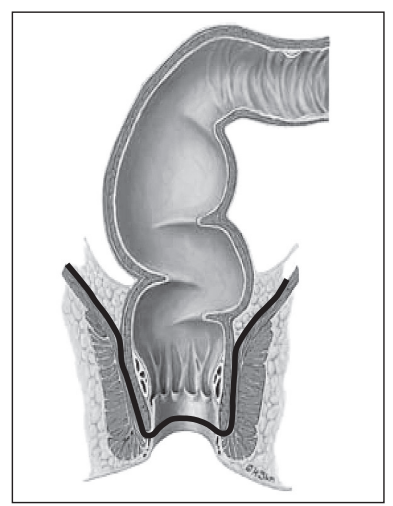

Figure 2. Four types of intersphincteric resection. (A) Partial resection of the upper internal sphincteric muscle. (B) Circumferential resection of the upper internal sphincteric muscle. (C) Partial preservation of the lower internal sphincteric muscle. (D) Total resection of internal sphincteric muscle.

tional of continence participated in present study. The median follow up time was 19 month (range, 12-30). The median operation time was $300 \mathrm{~min}$ (range, 219-381 min). Blood loss ranged from 1 to $183 \mathrm{ml}$ and none of the patients required transfusion. We did not encounter any intraoperative complication and open conversion was never re- quired. Out of the eight patients, only one developed a pelvic infection after surgery and was administrated antibiotics without percutaneous drainage. Other patients did not develop early postoperative small bowel obstruction or anastomotic leakage. Four months after surgery, the defunctioning ileostomy was routinely closed. One year after ileostomy 
closure, blinded observers assessed the patients using a fecal continence score (Wexner incontinence scale [WIS]). The median WIS score after 12 months was 7 (range, 2-18), which is very similar to that in a recent report in which the median WIS score of complete laparoscopic ISR and Jpouch-anal anastomosis was 6 (range, 2-10) ${ }^{5}$. Neither sexual nor urinary dysfunction was encountered in any patient. No patients had developed recurrent disease.

\section{Discussion}

We routinely create a colonic J-pouch in patients with low rectal cancer during open surgery ${ }^{6}$. In contrast, a coloplasty pouch is designed to interrupt antegrade colonic peristalsis and as an option when the pelvis is too narrow to permit a bulky colonic J-pouch-anal anastomosis and the descending colon is too short to reach the anus ${ }^{7)}$. Comparison of the stool frequency, use of antidiarrheal medication, and continence confirmed no significant differences between treatment with coloplasty pouch and colonic J-pouch ${ }^{7}$. Patients' perceptions measured by the Fecal Incontinence Quality of Life Scale also showed no difference between the colonic Jpouch and coloplasty pouch techniques ${ }^{7}$. In the present study, the WIS score of Lap-ISR with coloplasty pouch was similar to that of Lap-ISR with a colonic J-pouch which has been recently reported ${ }^{5}$. In addition, a laparoscopically constructed coloplasty pouch is easier to anastomose to the anus without tension in almost all cases. We have thus established a novel procedure, namely complete laparoscopic TME with ISR and coloplasty pouch anal anastomosis, to reduce the surgical invasiveness without any additional abdominal incisions other than those created for the laparoscopic port sites.

Though the results of present approach described here are very encouraging but needs to be confirmed further to ascertain its applicability for the treatment of patients with low rectal cancer. A very good result of anal function was recorded in patients even after 12 months of surgery. Technique is prone to the risk of postoperative abdominal infec- tions because the lumen of the large bowel is opened during laparoscopic construction of the coloplasty pouch. One patient had developed a surgical site infection but was cured following antibiotic treatment.

In conclusion, we have performed 8 surgeries involving Lap-ISR and coloplasty reconstruction without laparotomy. None of the patients developed severe complications, and we confirmed satisfactory short-quality of life and oncological outcomes. Therefore, we recommend this technique for patients with low rectal cancer.

\section{Conflicts of Interest}

The authors declare that there are no conflict of interest.

\section{References}

1. Joo JS, Latulippe JF, Alabaz O, et al. Long-term functional evaluation of straight coloanal anastomosis and colonic J-pouch: is the functional superiority of colonic J-pouch sustained? Dis Colon Rectum. 1998 Jun; 41(6): 740-6.

2. Teleky B, Jech B, Karner-Hanusch J, et al. Straight and colonic Jpouch reconstruction after low anterior resection. Acta Chir Iugosl. 2006; 53(2): 109-12.

3. Heriot AG, Tekkis PP, Constantinides V, et al. Meta-analysis of colonic reservoirs versus straight coloanal anastomosis after anterior resection. Br J Surg. 2006 Jan; 93(1): 19-32.

4. Orsenigo E, Di Palo S, Vignali A, et al. Laparoscopic intersphincteric resection for low rectal cancer. Surg Oncol. 2007 Dec; 16 Suppl 1: S117-20.

5. Beppu N, Matsubara N, Noda M, et al. Laparoscopic intersphincteric resection and $\mathrm{J}$-pouch reconstruction without laparotomy. Surg Today. 2015 May; 45(5): 659-62.

6. Kusunoki M, Inoue Y. Current surgical management of rectal cancer. Dig Surg. 2007 May; 24(2): 115-9.

7. Ho YH, Brown S, Heah SM, et al. Comparison of J-pouch and coloplasty pouch for low rectal cancers: a randomized, controlled trial investigating functional results and comparative anastomotic leak rates. Ann Surg. 2002 Jul; 236(1): 49-55.

Journal of the Anus, Rectum and Colon is an Open Access article distributed under the Creative Commons Attribution-NonCommercial-NoDerivatives 4.0 International License. To view the details of this license, please visit (https://creativecommons.org/licenses/by-nc-nd/4.0/). 